BMJ Surgery, Interventions, \& Health Technologies

\section{Long-term active surveillance of implantable medical devices: an analysis of factors determining whether current registries are adequate to expose safety and efficacy problems}

$\overline{\text { Samprit Banerjee, }{ }^{\oplus 1} \text { Bruce Campbell, }{ }^{2} \text { Josh Rising, }{ }^{3} \text { Allan Coukell, }{ }^{3} \text { Art Sedrakyan }{ }^{1}}$
To cite: Banerjee S, Campbell B, Rising J, et al. Long-term active surveillance of implantable medical devices: an analysis of factors determining whether current registries are adequate to expose safety and efficacy problems. BMJ Surg Interv Health Technologies 2019;1:e000011. doi:10.1136/ bmjsit-2019-000011

- Additional material is published online only. To view please visit the journal online (http://dx.doi.org/10.1136/ bmjsit-2019-000011).

Received 16 April 2019 Accepted 21 May 2019

D) Check for updates

(C) Author(s) (or their employer(s)) 2019. Re-use permitted under CC BY-NC. No commercial re-use. See rights and permissions. Published by BMJ.

${ }^{1}$ Healthcare Policy and Research, Weill Cornell Medical College, New York City, New York, USA

${ }^{2}$ University of Exeter Medical School, Exeter, UK

${ }^{3}$ Health Care Programs, The Pew Charitable Trusts, Washington, DC, USA

Correspondence to Dr Samprit Banerjee; sab2028@med.cornell.edu

\section{INTRODUCTION}

Ensuring the long-term safety and effectiveness of medical devices is critical to public health. Collecting outcomes through registries has exposed some high-profile failures of implanted devices, such as metal-on-metal hip prostheses. ${ }^{1}$ Well-established registries exist in many countries and more are being developed. Recently, the US Food and Drug Administration (FDA) began supporting registry-based efforts to expand the current infrastructure for recording the real-world performance of medical devices. ${ }^{2-5}$ However, the utility of registry-based active surveillance for detecting safety signals and efficacy concerns is by no means certain. Do they collect the key outcomes most likely to identify problems? Do they accrue sufficient numbers of patients to detect underperforming devices? Do they receive and review patient outcomes at appropriate intervals after implantation of devices? They need to produce relevant information in a timely way to help regulators and clinicians recognize devices with safety problems quickly. The data they provide can also help device manufacturers develop better next-generation products.

In this Analysis, we focus on four high-risk and widely used implanted medical devices: total hip replacement (THR) and total knee replacement (TKR) devices, stent grafts for endovascular aneurysm repair (EVAR), and surgical mesh implanted for pelvic organ prolapse (POP). We review evidence on device performance and analyze the likely numbers of patients whose data need to be recorded to detect a device which is performing significantly worse than expected. We review the current capacity of registries' active surveillance and the supporting infrastructure to conduct these analyses.

\section{LONG-TERM ACTIVE DEVICE SURVEILLANCE AND THE ROLE OF REGISTRIES}

Many questions about the long-term safety and effectiveness of medical devices remain unanswered at the time of a device's approval by a regulatory agency, because of the time required to gather sufficient data (especially data on long-term performance) and the high costs associated with data collection. An agreed plan for real-world long-term active surveillance can reduce preapproval data collection burden and give patients earlier access to new and safe technologies. The balance between preapproval and postapproval data collection required by regulatory agencies (eg, FDA) is gradually shifting. ${ }^{6}$ Traditionally, long-term active surveillance of device safety has relied on adverse event reports that physicians, healthcare institutions, manufacturers, and patients submit to the FDA and to regulators in other countries, and on regulator-required postapproval studies that manufacturers conduct. However, previous research has demonstrated the shortcomings of postapproval studies ${ }^{7}$ and adverse event reports: these include under-reporting and lack of denominator data to conduct population-level adverse event estimates. ${ }^{78}$

Registries offer a promising alternative or adjunct: they have exposed serious device-related problems in the past and recent reports have highlighted their potential. ${ }^{9-11}$ Linkage of registries and creation of coordinated registry networks (CRN) are likely to become an important method for tracking patient outcomes and assessing the performance of devices. 


\section{FOCUS ON PARTICULAR HIGH-RISK IMPLANTED DEVICES}

We chose four types of implanted devices as test cases, which are in frequent use and for which registries and CRNs are being developed, to track their performance:

- THR and TKR — as two separate device categories: Total joint replacement (TJR), both hip and knee, is the fastest growing elective device-based surgery worldwide. In the USA, over 400000 hip and 610000 knee replacements are performed annually, with combined numbers projected to reach 6 million by $2030 .{ }^{12-14}$

- EVAR: Abdominal aortic aneurysm (AAA) repair occurs more frequently in the USA (278 921) compared with the UK (29 300) during 2005-2012 yet aneurysm-related death is three times more likely in the UK compared with the USA. ${ }^{15}$ Aneurysms were traditionally treated by inserting a synthetic graft in a major open surgery, but now the most common approach is via a significantly less invasive endovascular procedure with a stent graft: this is EVAR. In 2012, over 30000 EVAR procedures were performed in the USA. ${ }^{16}$
- Surgical mesh for POP: Surgical mesh is often used in POP repair. In 2010, an estimated 300000 POP repairs were completed in the USA. ${ }^{17}$ There are current concerns about the safety of these procedures: 1 in 11 women experienced problems with vaginal mesh implants in the UK according to National Health Service (NHS) data on 92000 women from Hospital Episodes Statistics. ${ }^{18}$

For each type of device, we selected three primary outcome measures to assess the performance of each device. The choice of outcomes was based on the most commonly collected key data items, related to safety, effectiveness and/or patient-reported outcomes and are summarized in table 1 .

\section{DO REGISTRIES ENROLL SUFFICIENT NUMBER OF PATIENTS?}

The number needed to follow (NNF) is the number of patients a registry needs for a specific brand/type/class of device, to detect statistically significantly $(p<0.05)$ worse performance compared with a prespecified threshold.

Table 1 Summary and background for three measures chosen for each of the four devices

\begin{tabular}{ll}
\hline Measure chosen & Description \\
\hline Total hip/knee replacement & \\
\hline Harris Hip Score/Knee Society Score & Harris Hip Score (HHS) is a clinician-administered survey based on a 100-point scale to assess \\
& hip pain and function after surgery. \\
& Knee Society Score (KSS) is a validated 200-point scale to assess knee condition after surgical \\
& intervention.
\end{tabular}

Endovascular aneurysm repair (EVAR)

Endoleak Continued perfusion and pressurization.

- Considered as an effectiveness outcome..$^{40} 41$

- 20\%-25\% of EVAR procedures are complicated by endoleaks. ${ }^{42} 43$

- Excluding type II, the cumulative endoleak rate is $5.67 \%$ at 2 years. ${ }^{26}$

$\begin{array}{ll}\text { 30-day all-cause mortality } & \text { Most frequently used primary outcome in major clinical trials such as EVAR } 1 \text {, EVAR } 2 \text { and } \\ & \text { ACE. }{ }^{44-47} \\ \text { Secondary vascular intervention } & \text { Mortality varies from } 0.5 \% \text { to } 3.6 \%{ }^{48} \text { based on different studies and different EVAR grafts. }{ }^{40} 4149 \\ & \text { Major indications: endoleak, graft migration, kinking of limb grafts, stenosis and occlusions, and } \\ & \text { landing site enlargement. } \\ & \text { Reintervention rates are } 17 \% \text { for intermediate follow-up (up to } 4 \text { years) and } 23 \% \text { for a longer } \\ & \text { term follow-up (beyond } 4 \text { years) with a median of } 6 \text { years. }{ }^{51}\end{array}$

\begin{tabular}{|c|c|}
\hline \multicolumn{2}{|l|}{ Surgical mesh for POP } \\
\hline QoL & $\begin{array}{l}\text { King's College Pelvic Organ Prolapse Quality of Life (P-QoL) }{ }^{27-29} \text { is the most commonly used } \\
\text { validated questionnaire with nine domains. }\end{array}$ \\
\hline Total reoperation rate & $\begin{array}{l}\text { Reoperation due to postoperative complications and prolapse recurrence. } \\
\text { Total } 1 \text {-year reoperation rate is estimated to be } 3 \%-4 \% .^{30-32} \\
\text { Estimates for longer term (1.5-5 years) vary between } 8.5 \% \text { and } 13 \% .^{52} 53\end{array}$ \\
\hline Mesh erosion & $\begin{array}{l}\text { One of the most frequently experienced safety issues related to vaginal mesh is the risk of } \\
\text { vaginal-urethral erosion/extrusion. } \\
\text { Factors contributing to erosion include operative technique, implant size, and the specific } \\
\text { properties of the material (size, stiffness, elasticity and basic tissue compatibility, and so on). }{ }^{54} \\
110 \text { studies based on safety warning, issued by FDA in } 2011 \text { : approximately } 10 \% \text { of women } \\
\text { undergoing POP repair with mesh experienced mesh erosion within } 1 \text { year. }{ }^{1755}\end{array}$ \\
\hline
\end{tabular}

FDA, Food and Drug Administration; POP, pelvic organ prolapse. 
Appropriate choice of the threshold and of follow-up time for each device and outcome combination, used in our analysis, is described in more detail below. Operationally, the threshold for binary outcomes was a gold standard event rate and for continuous outcomes was a mean baseline or preoperative score. Then, the probability of detecting a significant departure from this gold standard or statistical power was calculated. For binary outcomes, this was a one-side test of proportions using the formula:

$$
\text { Power }=1-\beta=1-\Phi\left(\frac{\sqrt{n}\left(p_{0}-p_{1}\right)}{\sqrt{p_{1}\left(1-p_{1}\right)}}+z_{1-\alpha} \sqrt{\frac{p_{0}\left(1-p_{0}\right)}{p_{1}\left(1-p_{1}\right)}}\right)
$$

where $n=\mathrm{NNF}, p_{1}$ is the device performance rate and $p_{0}$ is the gold standard performance rate, $\Phi($.$) is the standard$ of a standard normal distribution, $\alpha=$ significance level and $1-\beta=$ power. Power for a generic binary outcome (table 2) forming compared with a gold standard performance rate per recommendations. ${ }^{19}$ For continuous outcomes, the power was computed for a one-sided alternative in a generalized estimating equations framework with a quasiscore-based test statistic ${ }^{20}$ assuming only one group, a linear effect of time and a range (0.05-0.50) of intraclass correlation coefficient, a parameter that accounts for correlations among repeated measures. Power for a generic continuous outcome (table 3) was calculated by considering small to moderate departures (0.3-0.5 SD) in the scale of Cohen's $d$ which is recommended for quality and patient-reported outcomes. ${ }^{21} 22$

Of note, these computations do not reflect missed follow-up measures, the rates of which vary widely with respect to procedures and outcomes. Our recommendation is to inflate NNF by appropriate context-dependent expected missing rates in the planning stage and in the analysis stage using statistical methods for ascertainment bias correction due to missing data such as robust or doubly robust methods (eg, inverse probability weighting or augmented inverse probability weighting) or use multiple imputation. ${ }^{23}$ Another important caveat is that our calculations do not account for subgroup analysis requirements (eg, hip implants performance in men and women separately) and the NNF needs to be adjusted if such subgroup comparisons are planned in advance.

\section{AT WHAT TIME POINTS SHOULD REGISTRIES EVALUATE DEVICE PERFORMANCE?}

The number of times a device is evaluated is conceptualized in two ways-'one look', when performance evaluation is performed at the end of a specified time period (eg, 30 days for 30-day mortality); and 'multiple looks' when performance evaluation is performed repeatedly at several time intervals (eg, 1, 5 and 10 years). While the choice of time intervals is guided by narrative review of literature, they are presented for illustrative purposes only and our methodology can be adopted for any choice of time point. Critically, however, the overall type I error normal cumulative distribution function, $z_{a}=a^{\text {th }}$ quantile was calculated for 1.5 times increased odds of underper-

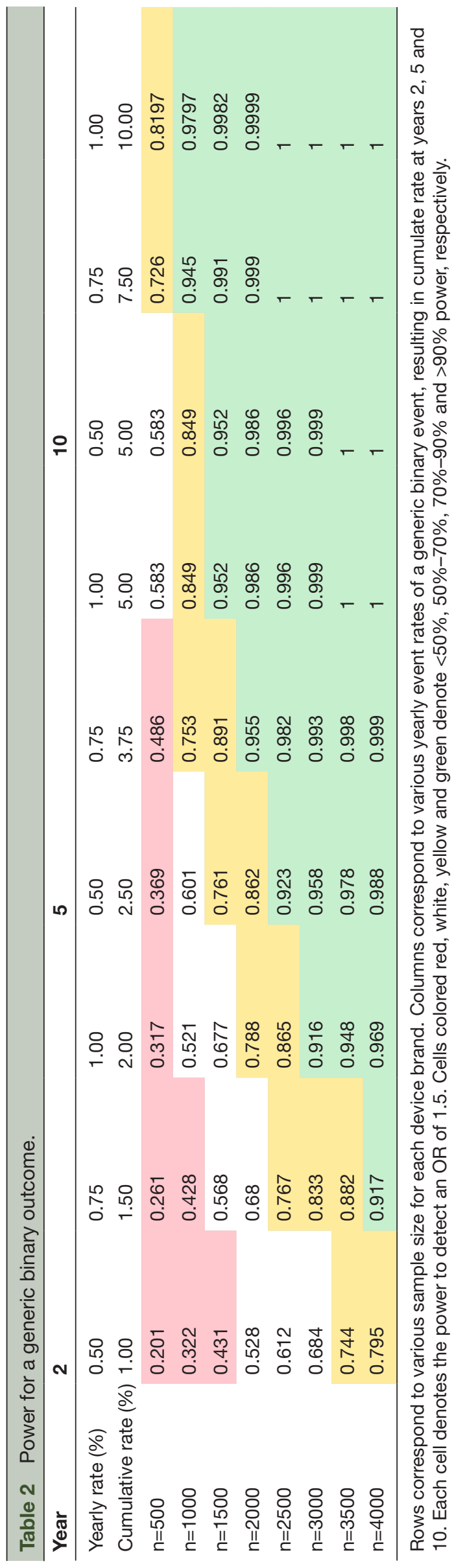

Banerjee S, et al. BMJ Surg Interv Health Technologies 2019;1:e000011. doi:10.1136/bmjsit-2019-000011 
Table 3 Sample size table for generic continuous outcome.

\begin{tabular}{|c|c|c|c|c|c|c|}
\hline \multirow[b]{3}{*}{ ICC } & \multirow[b]{3}{*}{ Power } & \multirow[b]{3}{*}{ Cohen's d } & \multirow[b]{2}{*}{ One look } & \multicolumn{3}{|c|}{ Long-term follow-up with multiple looks } \\
\hline & & & & 1 year & 5 years & 10 years \\
\hline & & & $\mathbf{n}$ & $\mathbf{n}$ & $\mathbf{n}$ & $\mathbf{n}$ \\
\hline 0.25 & 0.8 & 0.3 & 104 & 147 & 132 & 119 \\
\hline 0.5 & 0.8 & 0.3 & 69 & 98 & 88 & 80 \\
\hline 0.5 & 0.9 & 0.3 & 96 & 130 & 116 & 105 \\
\hline 0.05 & 0.8 & 0.5 & 47 & 68 & 60 & 55 \\
\hline 0.25 & 0.8 & 0.5 & 38 & 53 & 48 & 43 \\
\hline 0.5 & 0.8 & 0.5 & 25 & 36 & 32 & 29 \\
\hline
\end{tabular}

Rows correspond to various levels of power, intraclass correlation coefficient (ICC) and effect size (measured by Cohen's d). Columns provide sample size for one look or assessment and continual monitoring with multiple looks or assessments at 1, 5 and 10 years. The type I error for 'one look' is controlled at $5 \%$ and for 'multiple looks' is jointly controlled at $5 \%$ using Bonferroni's method.

or alpha, in every situation, should be controlled at $5 \%$ and adjusted for multiple looks, at certain time intervals, using a simple and conservative method such as Bonferroni's method (as we use here) or other alphaspending methods such as O'Brien-Fleming, Pocock or Lan-DeMets.

\section{WHAT INDICATES THAT A DEVICE IS NOT PERFORMING AS EXPECTED?}

The expected performance of devices at each follow-up time point was guided by a narrative review of literature (see online supplementary tables 1-4). When available (eg, endoleak endpoint after AAA) we gave priority to estimated thresholds from studies that conducted meta-analysis or meta-regression. In other instances, our estimated performance thresholds are conservative and a formal systematic review or meta-analysis is unlikely to change the results substantially.

\section{Hip and knee replacement}

Key outcomes were scores of physical function, quality of life (QoL) measures and revision rates. Our assessment of Harris Hip Score (HHS) showed that following a cohort of 341 patients will provide $>90 \%$ power to detect an underperforming device with a clinically meaningful change of 4.5 HHS points (or $d=0.3$ ) after 5 and 10 years (table 4 ). Similarly, our assessment for Knee Society Score showed that a cohort of 341 patients is required to provide $>90 \%$ power to detect an outlier device with a clinically meaningful change of 4.5 points (or $d=0.3$ ) at the end of 5 and 10 years.

Postoperative Short Form 12 (SF-12) is the most commonly used measure of general QoL. Using SF-12 we found that a cohort of 181 (66) patients is needed to identify a small (moderate) change of 1.4 (2.4) points for THR or 1.6 (2.7) points for TKR, for 'one look' at the end of 1 year with $90 \%$ statistical power.

Based on National Institute for Health and Care Excellence guidelines, ${ }^{24}$ rates of revision surgery for joint replacements should be $<5 \%$ at 10 years as a metric of good performance and is commonly assessed at years 2,5 , and $10 .^{25}$ Following up a cohort of 2500 patients for 5 years would have $>90 \%$ power to detect 1.5 times increased odds of revision compared with the annualized revision rate of $0.5 \%$.

\section{Endovascular aneurysm repair}

Three key outcomes are 30-day mortality, occurrence of endoleaks, and the need for secondary interventions (for endoleaks and other complications associated with the stent graft). Thirty-day all-cause mortality varies between $0.5 \%$ and $3.6 \%$ (see online supplementary table 3 ) with a best estimate around 2\%. Following up a cohort of 2200 patients would provide $>90 \%$ power to detect 1.5 times increased odds of 30-day all-cause mortality compared with the performance goal of $2 \%$ mortality.

A recent meta-regression ${ }^{26}$ estimated the cumulative rate of endoleak (excluding type II) occurrence to be $5.67 \%$ at 2 years or an annualized rate of $2.84 \%$. A cohort of 1400 participants would provide $>90 \%$ power to detect 1.5 times higher odds of endoleak occurrence at the end of 2 and 5 years. However, our NNF estimate is 525 to detect 1.75 times higher odds with $80 \%$ power that is similar to that estimated in Kent $e t a l$ s study. ${ }^{26}$

Secondary vascular interventions are estimated to occur at an annual rate of $4 \%$ (online supplementary table 3 ). 
Table 4 Number needed to follow (NNF) of three measures of four devices and a power of $>90 \%$

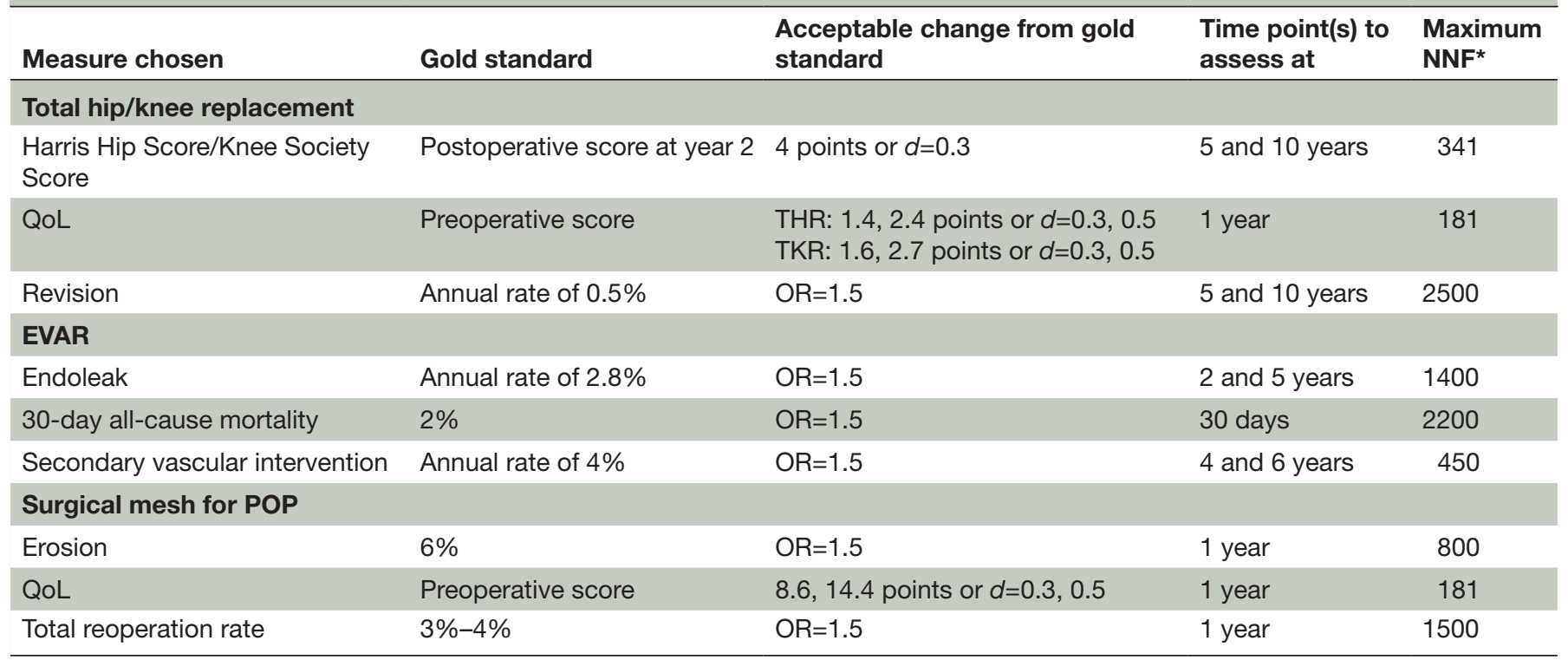

The gold standard for continuous outcomes is based on a baseline measure (before surgery or 2 years after surgery) and that for binary outcomes is based on gold standard rates from literature or expert opinion.

*The maximum is over multiple scenarios of gold standards and time points.

EVAR, endovascular aneurysm repair; POP, pelvic organ prolapse; QoL, quality of life;THR, total hip replacement; TKR, total knee replacement; $d$, Cohen's $d$.

With this performance goal, the NNF is 450 for 4 and 6 years (see table 1 ) to have $>90 \%$ power to detect 1.5 times increased odds of secondary vascular intervention.

\section{Surgical mesh for POP}

Key outcomes are QoL measures, mesh erosion and need for reoperation. Effectiveness outcomes in published reports on mesh repair are typically based on QoL scores (P-QoL) before and after the procedure. ${ }^{27-29}$ Following up a cohort of 181 patients has $>90 \%$ power to identify a clinically meaningful 8.6 point change in P-QoL for 'one look' at 1 year postoperatively.

Mesh erosion is an important safety endpoint, and a cohort of 800 women followed up for 1 year would provide $>94 \%$ power to detect 1.5 times higher odds for erosion compared with an overall erosion rate of $6 \%$ (see online supplementary table 4).

The risk of reoperation following POP repair with mesh due to postoperative complication or prolapse recurrence was estimated to be $3 \%-4 \%$ within 1 year. ${ }^{30-32} \mathrm{~A}$ cohort of 1500 patients would provide $>90 \%$ power to detect 1.5 times increased odds of reoperation.

\section{ARE CURRENT REGISTRIES SUFFICIENT?}

Our analyses suggest that registries do not need to follow unrealistically large cohorts to identify outlier performance of types of devices (eg, metal-on-metal hip implants). We evaluated current registry infrastructure to identifying deviations from expected performance of the devices considered using three objective criteria-whether the registry contains enough patient records, captures the relevant measures, and conducts enough longitudinal follow-upand found most registries either contain sufficient numbers of patients already or are expected to be so in future.

Specifically for hip and knee replacements, the American Joint Replacement Registry, Function and Outcomes Research for Comparative Effectiveness in Total Joint Replacement registry, the Kaiser-Permanente National Total Joint Replacement Registry, and the Michigan Arthroplasty Registry together have data on over 1 million TJRs annually but lack robust capture of functional and quality measures (eg, HHS, QoL). The US Vascular Quality Initiative (VQI), launched by the Society for Vascular Surgery in 2011, has over 350 participating centers across 46 US states and Ontario, and has collected data on over 32200 AAA repairs and adequately captures key performance measures. The Pelvic Floor Disorders Registry, founded to support US FDA recommendations for increased monitoring of transvaginal mesh use, began collecting data in late 2015 and is currently too new to conduct robust analyses. ${ }^{33}$

Of note, it is unclear if the current registries are sufficiently large for each device brand (eg, DePuy metalon-metal implant) because such details are not always recorded and future efforts to harmonize definitions need to be undertaken. In such scenarios, device classes could be studied by combining multiple brands and types (eg, compare metal-on-metal with metal-on-ceramic hip replacement devices).

\section{WHAT ARE THE OBSTACLES TO PROGRESS?}

Conducting long-term active surveillance is not easy and incomplete follow-up can limit the usefulness of registry 
data. This problem could be addressed by linking registries with other data sources (eg, insurance claims data in private health systems) that collect patient outcomes over extended periods of time (eg, efforts are underway to link the VQI with claims data resources, ${ }^{34}$ providing longer follow-up to evaluate secondary vascular intervention and possibly endoleak occurrence after device use). In the USA, the FDA has proposed a new National Evaluation System for Health Technology, ${ }^{3}$ which will integrate registries with claims data to provide long-term follow-up. This method is better suited for clinically measured safety or effectiveness outcomes (eg, revision surgery for joint replacement) than for patient-reported outcomes (eg, QoL) which requires direct data collection (eg, telephone interviews). In the UK, linkages with routinely collected NHS statistics, national mortality data and with the Clinical Practice Research Dataset ${ }^{35}$ are important linkages for long-term data acquisition.

Incorporation of patient-reported outcomes into longterm active device surveillance will remain a challenge, because registries, claims data, or electronic health records do not currently capture such outcomes. Registry organizers, manufacturers, and healthcare providers will all have a part to play in developing mechanisms to collect patient-reported outcomes.

\section{THE FUTURE}

Advancing technology will enable increasing amounts of useful data to be collected by device registries. Electronic health records, smartphone apps and wearable devices will enable a range of information, including patient-reported outcome measures, to be captured. Increasing capacity for data linkage offers huge potential, but this will need careful attention to its governance. International linkages will increase the power of information gathering, but will require attention to differing national data legislative requirements. Manufacturer's registries straddle national boundaries, but these need assurances of transparency and unbiased oversight to provide confidence in their data. Clear plans for the use of registries when new devices are presented for regulatory approval will help shift the balance that is required between premarket and postmarket evidence. It will allow earlier access to new products while providing assurance of a mechanism to monitor performance. The data from registries will help manufacturers to develop ever safer and more effective devices for future use.

\section{Collaborators Jialin Mao; Emma Briggs; Anqi Lu.}

Contributors SB and AS were responsible for the study concept and design and review the literature. SB was responsible for the statistical analysis and drafting the manuscript. All authors interpreted the data and contributed to writing the manuscript. All authors critically revised the manuscript for important intellectual content. BC played a major role in providing a global perspective to the study. AS supervised the study and was the guarantor.

Funding This project was partially supported by Pew Charitable Trusts and by the US Food and Drug Administration through grant 1U01FD005478.
Competing interests AS and SB received funding through Pew Charitable Trusts and the US Food and Drug Administration through grant 1U01FD005478.

Patient consent for publication Not required.

Provenance and peer review Commissioned; internally peer reviewed.

Open access This is an open access article distributed in accordance with the Creative Commons Attribution Non Commercial (CC BY-NC 4.0) license, which permits others to distribute, remix, adapt, build upon this work non-commercially, and license their derivative works on different terms, provided the original work is properly cited, appropriate credit is given, any changes made indicated, and the use is non-commercial. See: http://creativecommons.org/licenses/by-nc/4.0/.

\section{REFERENCES}

1. Sedrakyan A, Campbell B, Graves S, et al. Surgical registries for advancing quality and device surveillance. Lancet 2016;388:1358-60.

2. Food drug administration center for devices and radiological health. Guidance for industry and food and drug administration staff: use of real-world evidence to support regulatory decision-making for medical devices. FDA Maryland, 2017.

3. Shuren J, Califf RM. Need for a national evaluation system for health technology. JAMA 2016;316:1153-4.

4. Faris $\mathrm{O}$, Shuren J. An FDA viewpoint on unique considerations for medical-device clinical trials. N Engl J Med 2017;376:1350-7.

5. Sherman RE, Anderson SA, Dal Pan GJ, et al. Real-World Evidence What Is It and What Can It Tell Us? N Engl J Med 2016;375:2293-7.

6. Food, Administration D. Balancing premarket and postmarket data collection for devices subject to premarket approval. CDRH report, 2015.

7. Reynolds IS, Rising JP, Coukell AJ, et al. Assessing the safety and effectiveness of devices after US Food and drug administration approval: FDA-mandated postapproval studies. JAMA Intern Med 2014;174:1773-9.

8. Normand SL, Marinac-Dabic D, Sedrakyan A, et al. Rethinking analytical strategies for surveillance of medical devices: the case of hip arthroplasty. Med Care 2010;48(6 Suppl):S58-67.

9. Krucoff MW, Sedrakyan A, Normand S-LT. Bridging unmet medical device ecosystem needs with strategically coordinated registries networks. JAMA 2015;314:1691-2.

10. The Brookings Institution. Strengthening patient care: building an effective national medical device surveillance system, 2015.

11. Medical Device Epidemiology Network. Recommendations for a national medical device evaluation system, 2015.

12. Steiner C, Andrews R, Barrett M. HCUP projections: Mobility/ Orthopedic procedures 2011 to 2012. U.S. Agency for Healthcare Research and Quality, 2012.

13. Prevention CfDCa. NCHS, National Hospital Discharge Survey. 2005 annual summary with detailed diagnosis and procedure data, December 2007 centers for disease control and prevention, 2014. Available: http://www.cdc.gov/nchs/about/major/hdasd/listpubs.htm

14. Kurtz S, Ong K, Lau E, et al. Projections of primary and revision hip and knee arthroplasty in the United States from 2005 to 2030. The Journal of bone and joint surgery American volume 2007;89:780-5.

15. Karthikesalingam A, Vidal-Diez A, Holt PJ, et al. Thresholds for abdominal aortic aneurysm repair in England and the United States. N Engl J Med 2016;375:2051-9.

16. Quality AfHRa. HCUPnet: agency for healthcare research and quality, 2015. Available: http://hcupnet.ahrq.gov/HCUPnet.app/

17. Administration USFaD. Urogynecologic surgical mesh: update on the safety and effectiveness of transvaginal placement for pelvic organ prolapse, 2011

18. News BBC. Vaginal mesh operations should be banned, says NICE, 2017. Available: http://www.bbc.com/news/health-42110076

19. Mello MM, Goodman SN, Faden RR. Ethical considerations in studying drug safety - the Institute of Medicine report. Mass Medical Soc 2012.

20. Liu G, Liang K-Y. Sample size calculations for studies with correlated observations. Biometrics 1997;53:937-47.

21. Norman GR, Sloan JA, Wyrwich KW. Interpretation of changes in health-related quality of life: the remarkable universality of half a standard deviation. Med Care 2003;41:582-92.

22. Revicki D, Hays RD, Cella D, et al. Recommended methods for determining responsiveness and minimally important differences for patient-reported outcomes. J Clin Epidemiol 2008;61:102-9.

23. Little RJ, Rubin DB. Statistical analysis with missing data. John Wiley \& Sons, 2014.

24. Excellence NIfHaC. Total hip replacement and resurfacing arthroplasty for end-stage arthritis of the hip: technology appraisal guidance, 2014. 
25. Singh JA, Schleck C, Harmsen S, et al. Clinically important improvement thresholds for Harris hip score and its ability to predict revision risk after primary total hip arthroplasty. BMC Musculoskelet Disord 2016;17.

26. Kent F, Ambler GK, Bosanquet DC, et al. The safety of device registries for endovascular abdominal aortic aneurysm repair: systematic review and meta-regression. Eur J Vasc Endovasc Surg 2018;55:177-83.

27. Feldner PC, Castro RA, Cipolotti LA, et al. Anterior vaginal wall prolapse: a randomized controlled trial of SIS graft versus traditional colporrhaphy. Int Urogynecol J 2010;21:1057-63.

28. Maher CF, Feiner B, DeCuyper EM, et al. Laparoscopic sacral colpopexy versus total vaginal mesh for vaginal vault prolapse: a randomized trial. Am J Obstet Gynecol 2011;204:360.e1-7.

29. Hviid U, Hviid TVF, Rudnicki M. Porcine skin collagen implants for anterior vaginal wall prolapse: a randomised prospective controlled study. Int Urogynecol J 2010;21:529-34.

30. Chughtai B, Mao J, Buck J, et al. Use and risks of surgical mesh for pelvic organ prolapse surgery in women in New York state: population based cohort study. BMJ 2015;350:h2685

31. Kelly EC, Winick-Ng J, Welk B. Surgeon experience and complications of transvaginal prolapse mesh. Obstet Gynecol 2016;128:65-72.

32. Chughtai B, Barber MD, Mao J, et al. Association between the amount of vaginal mesh used with mesh erosions and repeated surgery after repairing pelvic organ prolapse and stress urinary incontinence. JAMA surgery 2016.

33. Bradley CS, Visco AG, Weber LeBrun EE, et al. The pelvic floor disorders Registry: purpose and development. Female Pelvic Med Reconstr Surg 2016;22:77-82.

34. Hoel AW, Faerber AE, Moore KO, et al. A pilot study for long-term outcome assessment after aortic aneurysm repair using Vascular Quality Initiative data matched to Medicare claims. J Vasc Surg. In Press 2017;66:751-9.

35. Herrett E, Gallagher AM, Bhaskaran K, et al. Data resource profile: clinical Practice Research Datalink (CPRD). International Journal of Epidemiology 2015;44:827-36.

36. U.S. Food and Drug Administration. Summary of Safety and Effectiveness Data (SSED)-Ceramic Total Hip System: U.S. Food and Drug Administration, 2009. Available: http://www.accessdata.fda. gov/cdrh_docs/pdf3/P030042b.pdf

37. D'Antonio J, Capello W, Manley M, et al. Alumina ceramic bearings for total hip arthroplasty: five-year results of a prospective randomized study. Clinical orthopaedics and related research 2005;436:164-71.

38. MacDonald SJ, McCalden RW, Chess DG, et al. Metal-on-metal versus polyethylene in hip arthroplasty: a randomized clinical trial. Clin Orthop Relat Res 2003;406:282-96.

39. Hooper GJ, Rothwell AG, Stringer M, et al. Revision following cemented and uncemented primary total hip replacement: a sevenyear analysis from the New Zealand joint registry. J Bone Joint Surg Br 2009;91:451-8.

40. Administration USFaD. Summary of Safety and Effectiveness Data (SSED) - Talent Abdominal Stent Graft System: U.S. Food and Drug
Administration, 2008. Available: http://www.accessdata.fda.gov/ cdrh_docs/pdf7/p070027b.pdf

41. U.S. Food and Drug Administration. Summary of Safety and Effectiveness Data - Powerlink System: U.S. Food and Drug Administration, 2004. Available: http://www.accessdata.fda.gov/ cdrh_docs/pdf4/p040002b.pdf

42. Hellinger JC. Endovascular repair of thoracic and abdominal aortic aneurysms: pre- and postprocedural imaging. Tech Vasc Interv Radiol 2005;8:2-15.

43. Veith FJ, Baum RA, Ohki T, et al. Nature and significance of endoleaks and endotension: summary of opinions expressed at an international Conference. J Vasc Surg 2002;35:1029-35.

44. Greenhalgh RM, Brown LC, Kwong GP. Comparison of endovascular aneurysm repair with open repair in patients with abdominal aortic aneurysm (EVAR trial 1), 30-day operative mortality results: randomised controlled trial. Lancet 2004;364:843-8.

45. Endovascular aneurysm repair and outcome in patients unfit for open repair of abdominal aortic aneurysm (EVAR trial 2): randomised controlled trial. The Lancet 2005;365:2187-92.

46. Lederle FA, Freischlag JA, Kyriakides TC, et al. Outcomes following endovascular vs open repair of abdominal aortic aneurysm: a randomized trial. JAMA 2009;302:1535-42.

47. Becquemin J-P. The ACE trial: a randomized comparison of open versus endovascular repair in good risk patients with abdominal aortic aneurysm. J Vasc Surg 2009;50:222-4. discussion 4.

48. Stather PW, Sidloff D, Dattani N, et al. Systematic review and metaanalysis of the early and late outcomes of open and endovascular repair of abdominal aortic aneurysm. Br J Surg 2013;100:863-72.

49. U.S. Food and Drug Administration. Summary of safety and probable Benefit-Ovation abdominal stent graft system: U.S. Food and drug administration, 2011. Available: http://www.accessdata.fda.gov/ cdrh_docs/pdf10/h100008b.pdf

50. Becquemin J-P, Kelley L, Zubilewicz T, et al. Outcomes of secondary interventions after abdominal aortic aneurysm endovascular repair. $J$ Vasc Surg 2004;39:298-305.

51. Paravastu SCV, Jayarajasingam R, Cottam R, et al. Endovascular repair of abdominal aortic aneurysm. Cochrane Database Syst Rev 2014;50.

52. Diwadkar GB, Barber MD, Feiner B, et al. Complication and reoperation rates after apical vaginal prolapse surgical repair. Obstetrics \& Gynecology 2009;113:367-73.

53. Morling JR, McAllister DA, Agur W, et al. Adverse events after first, single, mesh and non-mesh surgical procedures for stress urinary incontinence and pelvic organ prolapse in Scotland, 1997-2016: a population-based cohort study. Lancet 2016.

54. Mistrangelo E, Mancuso S, Nadalini C, et al. Rising use of synthetic mesh in transvaginal pelvic reconstructive surgery: a review of the risk of vaginal erosion. J Minim Invasive Gynecol 2007;14:564-9.

55. Abed H, Rahn DD, Lowenstein L, et al. Incidence and management of graft erosion, wound granulation, and dyspareunia following vaginal prolapse repair with graft materials: a systematic review. Int Urogynecol J 2011;22:789-98. 